\title{
Hacia una Filosofía Política de la Diferencia ${ }^{1}$
}

\section{Towards a Political Philosophy on the Difference}

\author{
Camilo Enrique Rios Rozo* \\ Consejo Nacional de Investigaciones Científicas y Técnicas (CONICET) \\ Buenos Aires, Argentina \\ cerrsociologicus@gmail.com \\ Jimmy Ortiz Palacios** \\ Universidad Distrital Francisco José de Caldas \\ ephemeralreturn@gmail.com
}

Fecha de recepción: 15 de julio de 2014

Fecha de aceptación: 1 de septiembre de 2014

\section{Resumen}

Caracterizando como alternativa las reflexiones en torno a la noción de "diferencia" que hacen autores como Lazzarato, Virno, Agamben, 'Bifo', Rancière y Negri, entre otros, acerca de las posturas políticas que, o bien parten de la identidad sociológica, o bien de la igualdad o el acuerdo como axioma de lo político, el texto propone un llamado de atención respecto de la necesaria ampliación que, en la concepción de lo político, implican estas perspectivas, sobre todo entendiéndolas como prisma de análisis de los procesos de producción de subjetividades en nuestros tiempos.

Palabras clave: Diferencia, Filosofía contemporánea, Política, subjetivación.

\footnotetext{
${ }^{1}$ Este es el título original del presente artículo, presentado inicialmente como ponencia en la I Jornada Internacional "Filosofía, Estudios Políticos y Diferencia", realizado en Bogotá, Universidad de La Salle, entre el ${ }^{21} \mathrm{y} \mathrm{el}^{23}$ de mayo de 2014.

"Becario Doctoral del Consejo Nacional de Investigaciones Científicas y Técnicas (CONICET). Buenos Aires, Argentina. Sociólogo (UNAL) y Mg. en Sociología de la Cultura y Análisis Cultural (IDAES-UNSAM). cerrsociologicus@gmail.com.

"*studiante de Licenciatura en Educación Básica con Énfasis en Humanidades y Lengua Castellana en la Universidad Distrital Francisco José de Caldas. Participante del núcleo de lectura de la Línea de Investigación "Genealogía de las Subjetividades Contemporáneas". ephemeralreturn@gmail.com
} 


\begin{abstract}
To characterize as alternative the reflections on the notion of "difference", that authors as Lazzarato, Virno, Agamben, 'Bifo', Rancière, and Negri, among others, do about the political positions that either start from the sociological identity either equality or the agreement as a politics' axiom, this paper is a call of attention on the necessary extension of the political conception field that imply these points of view, especially understanding them as a prism to analyze our times of the subjectivities processes' production.
\end{abstract}

Keywords: Contemporary Philosophy, Difference, Politics, Subjetivation

En la esfera recombinante, el poder es inaprensible, porque no está en ninguna parte y está en todas al mismo tiempo. Pero esto posibilita, también, transformar todo el cuadro a partir de un nuevo elemento, un signo, un virus.

-'Bifo'-

\title{
1. Presentación
}

¿Por qué seguir hablando de lo político hoy?, pero, a la vez, ¿cómo dejar de hacerlo? Este texto es apenas una primera aproximación a una idea que ha ocupado conversaciones, tertulias y encuentros de diferentes tipos, y que ahora empieza a tomar forma; no es nuestra intención con él 'cerrar' o demarcar una discusión, sino apenas trazar unos primeros elementos que puedan, si acaso, alentarla. El campo político, creemos, y acá empezaríamos a encarar tímidamente las preguntas con las que abrimos, es uno que ha echado sus raíces sobre una multiplicidad de ideas y conceptos que, en todo caso, han dejado por fuera la idea de la diferencia en términos fuertes. Sin duda, se trata de un enunciado atrevido y ambicioso. Es apenas nuestra primera intuición. $\mathrm{Y}$ en este artículo intentaremos, entre otras cosas y de modo más bien desorganizado, poner a prueba su potencia en función de una suerte de filosofía de la diferencia que puede terminar por resquebrajar lo político tratando de defenderlo. Es un riesgo que asumimos desde el ejercicio del pensamiento, siguiendo por el momento, sobre todo, a siete autores -y a muchos otros que quedan tácitos, como no puede ser de otra forma-: Maurizio Lazzarato y Franco Berardi 'Bifo'; Antonio Negri, Michael Hardt y Paolo Virno, y Jacques Rancière y Giorgio Agamben. Hemos decidido, por alguna razón que pasa por lo estilístico, pero sobrepasa cualquier explicación posible -sin que sea una arbitrariedad puramente caprichosa-, agrupar a los siete autores en estos tres grupos señalados $\mathrm{y}$, de esa misma forma, los presentaremos. Debe entenderse, en todo caso, que tanto la 
agrupación como la presentación son puramente analíticas, cosa de la que intentaremos también dar cuenta sobre el final del texto con algunas precisiones generales.

Así pues, sentimos en su pensamiento un movimiento más o menos común: el de pensar la política desde la diferencia, el de darle a la diferencia un estatuto ontológico - gesto que sería profundamente deleuziano, autor del que no haremos mayor uso en este trabajo- tanto para adelantar un diagnóstico del presente, como para lanzar una propuesta de transformación de las condiciones de posibilidad de los procesos de subjetivación en nuestros contextos.

Pero antes de dar cuenta de lo que estos autores concretos proponen y lanzan sobre la mesa -cosa que haremos de manera extremadamente breve-, intentaremos construir nuestra hipótesis de lectura de lo político, sobre la que la propuesta de estos y otros autores se levanta para excavar sus cimientos.

\section{Contexto General del Campo Político}

Quisiéramos ir hasta la Polis griega para dar cuenta de lo que hoy entendemos por lo político. Antes de que fuera un campo de saber propiamente dicho, la noción de $T a$ Politiká daba cuenta al mismo tiempo de una forma de comportamiento específico (el que debía tenerse en la Polis) y de los mecanismos necesarios y recomendados para hacer de ese comportamiento un escenario de participación y construcción más o menos colectivo - algo muy parecido, desde ese momento, y guardando todas las distancias, a la 'democracia'-. Fue mucho después que la política se consolidó como un escenario epistémico cerrado sobre sí mismo y que delimitó sus propios códigos de producción y de gobierno de lo común.

Los pensadores de la política, más o menos como la conocemos hoy, se alimentan de esa historia etimológica y filosófica de las prácticas del campo político. Sin embargo, en ese plano de discontinuidad resulta al menos interesante que uno de los discursos que consolida el campo político sea el de la democracia. Uno entre muchos posibles, como sucede en cualquier campo de saber. Así, la genealogía de la política se diría en términos de la genealogía de la democracia e iría hasta la antigua Polis griega. Esto no quiere decir que la democracia sea la única forma de la política, pero sí que es la forma que adquirió de manera más o menos predominante -genealógicamente hablando-en la historia de la humanidad.

De ahí que podríamos decir que con Hobbes aparece la primera 'filosofía política'. Lo que hace Hobbes es dialogar con la idea aristotélica de que la Polis opera como una colmena y que por lo tanto es un cuerpo. Hobbes dialoga con esta idea de manera 
agresiva y sostiene que existen individuos egoístas que se encuentran, básicamente, en una situación de competencia: hay un estado 'pre-político' que genera 'inseguridad'. Ante este panorama, pensar en un 'contrato social' en el que el Estado opere como un 'árbitro' no es descabellado. Frente a Aristóteles, Hobbes entonces sostendrá que el Estado, la política (la historia de la política también se dice en términos de la historia de las instituciones; sobre este punto volveremos más adelante para señalar una posible apertura de esta concepción de la política que pueda dar cuenta también de lo político), se dedicará a garantizar las libertades individuales y no el bien común -como en la colmena griega de Aristóteles-.

De la mano de esta primera filosofía política, es posible ubicar la emergencia de la economía política (Adam Smith) y su postulado de la 'mano invisible' que termina proponiendo que potenciar al Estado se logra potenciando las competencias (económicas) de los individuos. De igual forma, el utilitarismo del siglo XVIII sostiene sus postulados sobre la idea de la existencia más o menos natural de un individuo egoísta que haría de la naturaleza humana la del 'homo oeconomicus' (maximizar beneficios minimizando dolor). En esta perspectiva, el Estado debe dedicarse a procurar el mayor placer posible al mayor número de individuos posible.

Estos elementos consolidan lo que conocemos desde hace más o menos cuatro siglos como 'política'. El liberalismo político, entonces, hunde sus raíces en la misma Polis griega, con la que se instala una tensión más bien aparente, puesto que en ese esquema también se establecen mecanismos en los que la Ta Politiká debe ser fortalecida -más allá de cuál fuera su contenido nominal-por encima de cualquier cosa. En la Polis griega, así como en el pensamiento filosófico-político general, a la idea de diferencia se le concede existencia bajo la condición de ser concebida como un 'mal necesario', como un estadio a superar bajo estrategias formales diversas.

Este trabajo, entonces, no propone un análisis de la democracia -cosa por demás pendiente y pertinente-, sino del papel de la noción de 'diferencia' en el pensamiento filosófico de la política. Nuestro análisis, no obstante, se levanta sobre la clave de lectura que sostiene que el pensamiento político genealógicamente dominante, nunca ha otorgado a la noción de 'diferencia' un estatuto ontológico para sí, ya que esto le costaría algunas de sus premisas básicas. Al mismo tiempo, sostenemos que, a partir del pensamiento de algunos autores contemporáneos, es posible empezar a pensar una filosofía política de la diferencia que, con alguna suerte, no termine por implosionar la política misma, sino que, más bien, permita ampliar y complejizar el panorama de lo político en nuestros tiempos. 


\section{La Noción de Diferencia en la Filosofía Política Contemporánea}

Si seguimos la hipótesis de lectura propuesta, la política será concebida, hasta el momento, como un aparato institucional, representativo y procedimental que hace de la diferencia un escenario de encuentro para superar, mas no como un primado ontológico de su propia existencia. Frente a esta noción acotada de lo político es que los autores aquí estudiados proponen no solo una salida sino una re-construcción filosófica profunda.

\subsection{La filosofía del acontecimiento y el virus como acción política: 'Bifo'- Lazzarato}

Tanto 'Bifo' (2003, 2007, 2010) como Lazzarato $(2006,2007)$ son pensadores de la diferencia, como vía y como escenario de lo político por excelencia; cada uno, desde rincones biográficos particulares, herederos del pensamiento de Foucault y de Deleuze; el primero, vía Guattari, con quien sostuvo una amistad muy interesante a pesar de su clara no coincidencia en temas de militancia, y el segundo, vía Deleuze y la filosofía propiamente de la diferencia. Además, son dos autores fuertemente involucrados con procesos sociales concretos, que de alguna forma movilizaron su reflexión teórica de manera inédita. En fin, una pareja que comparte los rasgos de un pensamiento filosófico y sociológico al mismo tiempo aterrizado y voraz, así como un lenguaje atrevido y profundamente creador. Veamos.

Franco Berardi 'Bifo', en el cuadro que realiza de lo contemporáneo, señala que la base de los movimientos sociales del siglo XX, es decir, la totalización y la dialéctica, se ve re-configurada por las nuevas formas productivas que sustituyen la base de la totalización por la recombinación. Ahora los "actores" se multiplican, proliferan, haciendo que el panorama sea infinito y no-homogenizable. Al parecer, lo que 'Bifo' presenta es la manera como lo inaprensible y lo imprevisible funcionan hoy como estrategias virulentas de contagio. Estas se esparcen como un virus que permite transformar las cosas; pero, y aquí vale la pena precisar, esta transformación ocurre a partir de lo particular, de lo singular y ya no desde las formas totalizantes y dialécticas características del siglo XX. En estos días lo que hay son multiplicidades que no caben en un campo de totalización, que como nos dice 'Bifo', está destinado al fracaso, a la ineficacia. Lo anterior, dado que el poder está en todas partes y en ninguna, razón por la cual lo que funciona hoy es lo viral: virus que se multiplican, contagian, atacan y, después, se vuelven a transformar en otra cosa. ¿En qué otra cosa? En cualquiera.

El campo político contemporáneo es el espacio de la existencia misma, de lo que se trata es de subvertir los signos, de re-diseñar los modelos establecidos; pensar en los modos posibles de transformar lo "ya transformado". Por consiguiente, se deben 
crear condiciones de posibilidad existencial. En este sentido, el estatuto de la diferencia se puede pensar en términos de subjetiv-acción y ya no como "sujeto histórico", del cual nos habló el marxismo. La diferencia como espacio vectorial, rizomático, donde el sujeto ya no se piensa como anterioridad ontológica, como algo dado y establecido, sino en tanto proceso constituyente -y no constituido-. Esto implica pensar en procesos de subjetivación donde no hay identificación social fija sino continuo cambio de las relaciones sociales. En este espacio de la diferencia, la fuerza -que ya no será entendida como violencia- debe operar como potencia posible de transformación de las relaciones sociales, de los modos de estar-en-elmundo. La fuerza emerge como posibilidad otra de vida; como re-existencia ${ }^{2}$, más que como resistencia.

La diferencia ya no referirá a un "otro" (alter) sino que se definirá en tanto acción estratégica de reinvención de los campos (económicos, tecnológicos, políticos, etc.) y creación de nuevas cosas, de nuevas relaciones que amplíen los límites de lo posible en la actualidad, lo que incluso puede significar la implosión de esos mismos 'campos' desde su existencia significante.

En ese mismo sentido, Lazzarato, bebiendo de las aguas de Leibniz, de Tarde e, incluso, de Bajtin, leerá la política contemporánea como 'noo-política'. Lo que quiere decir esto es que, mucho más acá de cualquier proceso de institucionalización del ejercicio de gobierno, el poder tiene como objeto la mente y los marcos cognitivos de lo que antaño llamaríamos 'población' y que ha devenido 'público'. Como en 'Bifo', la perspectiva de Lazzarato parte de un llamado de atención a propósito de las nociones desde las que pensamos el fenómeno de la política en nuestros tiempos:

[...] este continuum es un conjunto de discontinuidades, de umbrales, de divisiones, de segmentos que las tecnologías de seguridad permiten gobernar como un todo, como una misma población. Lo propio del gobierno será entonces localizar las "diferencias" de estatus, ingresos, formación, garantías sociales, etcétera, y de hacer jugar eficazmente las desigualdades unas contra otras (2006, p. 13).

De nuevo, la política como un escenario en el que la diferencia, ahora constitutiva de lo social, es concebida patológicamente o, en el mejor de los casos, como un campo estratégico de intervención desde la homogenización (discursiva y normativa).

\footnotetext{
${ }^{2}$ Cf. Ríos, Camilo. (2012). "Un nuevo terreno de lucha". En "Configuración de subjetividades en sociedades de control". Tesis de maestría no publicada. Universidad Nacional de General San Martín (UNSAM). Instituto de Altos Estudios (IDAES). Allí se esboza lo que puede llegar a ser una re-existencia, y esta, como apuesta ético-estético-política.
} 
A renglón seguido, Lazzarato establece la complejidad que implica el paso de un pensamiento político estructurado en el binarismo (lucha de clases) a uno que construya su fundamentación en la multiplicidad y en la diferencia: es mucho más 'raro,' dice. Partiendo de esta última perspectiva, entran a ser considerablemente más relevantes aspectos relacionados con el conflicto constitutivo de lo social y de lo político también, aspectos como la relación bidireccional y correlativa entre lo molar y lo molecular, así como lo relacionado con los procesos de constitución de cada una de esas dimensiones respecto, sobre todo, de sí misma.

La tradición política occidental constituyó como política de la totalidad y la universalidad [...] Hay aquí un problema político-filosófico fundamental, porque estoy convencido de que una recuperación de la iniciativa política y el desarrollo de movimientos no se puede hacer sino sobre la base de una política de la multiplicidad y de la singularidad (Lazzarato, 2006, pp. 27-28).

Esto implica pensar filosóficamente diferente las relaciones como 'flotantes', 'variadas', 'fluidas', para salir definitivamente del pensamiento de la universalidad y sumergirnos en el de la diferencia como constitutiva de la vida en lo político.

Hay en el planteo de Lazzarato resonancias importantes con el pensamiento de 'Bifo', sobre todo en el sentido de que ambos llaman la atención fuertemente a propósito de una necesaria renuncia frente a la tentación de pensar cualquier esencialismo, sustancialismo o estructuralismo fundante, cosa que, además, es lo que posibilita re-pensar la noción misma de 'relación', ahora como acción virulenta. La herencia deleuziana, en este aspecto, parece absolutamente clara.

De este punto, la filosofía política de Lazzarato, como la de 'Bifo', se inserta en lo que conocemos como 'filosofía del acontecimiento', espacio del pensamiento contemporáneo que no podemos abordar en este breve análisis. El camino, en todo caso, se traza como uno de desmitificación de cualquier esencialismo (marxista, sobre todo); llamado de atención sobre el carácter constitutivo del acontecimiento como ontología de la discontinuidad, de la multiplicidad, de la singularidad y de la diferencia; y fundamentación monadológica de la acción política (Tarde). De este último, Lazzarato rescatará como directriz algo que presupone también 'Bifo', que el modo de existencia es, antes que nada, la diferencia misma; existir es, fundamentalmente, ser diferente, diferir. Desde ahí se piensa la política en ambos autores. 


\subsection{Actualizaciones desde el marxismo, resonancias de la diferencia: Hardt/Negri-Virno}

El diagnóstico que hacen Negri (2006) y Hardt y Negri (2006a, 2006b)del Imperio, que remite a una ontología en tanto producción de formas (de vida) y que, por lo tanto, implica una red de interconexión de 'todo', permite pensar también en términos ontológicos las alternativas. En ese sentido, abrazar lo inconmensurable como grilla de observación, es al mismo tiempo una 'vuelta de tuerca' sobre la metafísica, y una alteración del sentido de la política. En términos aritméticos, la virtualidad es la diferencia misma como potencia constitutiva ontológica del sujeto. Lo que hacen Hardt y Negri es operar esa noción en términos no solo de análisis filosófico, sino de propuesta política que articule el paso de lo virtual a lo real deleuziano, como acción de la singularidad de lo común -que no es otra cosa que la institución de lo diferente en tanto tal-. Las acciones del Imperio, políticamente hablando, y desde el punto de vista de la constitución del poder, son básicamente reactivas y homogeneizadoras; procuran avanzar hacia el orden, cortando los brotes de desorden, no generando las condiciones de producción del orden mismo. La idea, entonces, es que la resistencia está primero. Y acá, de nuevo, resuena Deleuze, sobre todo si recordamos el breve artículo titulado Deseo y placer (2007).

De este modo, el primer estatuto de la diferencia, política y operativamente hablando, debe realizarse en el espacio: la multitud es una caja de resonancia que amplifica los sentires tanto del nomadismo como del mestizaje, ya que al borrar las categorías espaciales constituidas, puede expandir la diferencia como modo subjetivo de vida básico, sin que eso signifique la homogeneización de la diferencia, sino muy por el contrario, el hecho de darle deleuzianamente estatuto ontológico a la diferencia misma. No se trata, de esta manera, de borrar fronteras para ser todos iguales, sino para reconocer en la diferencia constitutiva la potencia de la creación.

Como en el Imperio, trabajo y cognitividad se unen, la vida es el trabajo y el trabajo es la vida, haciendo del modo de existencia una situación unificada, no puede sino decirse que la salida, tome la forma que tome, será una apuesta por la diferencia, la ruptura de la unificación del proceso de producción en términos del trabajo, por ejemplo, y en términos de la vida y de lo inmaterial.

Vis a vis, la lectura que hace Virno (2011) del ámbito político contemporáneo, sin desembocar en el Imperio y sin proponer la multitud de manera idéntica a Hardt y Negri, concuerda en el sentido de que, haciendo una actualización del marxismo, identifica sus alcances en términos de articulación desde allí de una alternativa política contundente. El mundo ha cambiado, y en el espectro de análisis de Virno se dibuja claramente una genealogía de la política que se dice en términos de 
codificación, de igualación normativa tanto de los comportamientos efectivos de las personas, como de sus expectativas e ilusiones. Esta homogeneización es el modus operandi de la política más o menos desde siempre, y es lo que hace que, encontrándose en este punto con los autores de Imperio, el ejercicio de gobierno penetre de manera más o menos indiferenciada sobre los 'modos de vida' y los configure, modulando 'genéticamente' las condiciones de posibilidad de los procesos de subjetivación.

La paradoja está en el hecho de que la apertura generada por esta traducción infinita de los procesos de homogeneización, por ejemplo en tanto producción y gobierno del deseo, es lo que permite al mismo tiempo un accionar que, desde esas mismas dimensiones, restituya la diferencia como escenario no de lucha sino de producción subjetiva en la singularidad misma. De una perspectiva de clase, se pasa a una que podemos llamar de resonancia de la diferencia -en Hardt y Negri se dice como 'multitud', y en Virno, como ambivalencia constitutiva-.

\subsection{La potencia de/en la diferencia: Rancière-Agamben}

Aproximándonos a las apuestas de esta última pareja, parece posible señalar algunos puntos de anclaje en sus trabajos, no para indicar que sus proyectos políticos sean los mismos o se dirijan hacia un objetivo compartido, pero sí en la apuesta dirigida hacia una des-identificación política. Tal parece que tanto para Agamben $(2005,2010)$ como para Rancière (1996, s.f.) el problema de la política contemporánea se encuentra en el hecho de pensar la des-identificación como espacio abierto de acción, como campo que permite crear nuevas formas-de-vida (Agamben) y ejercicio de des-subjetivación (Rancière). Este nuevo espacio de posibilidad ya no se encuentra reducido a unas identidades sociales fijas e inmutables (representativas), sino que requiere necesariamente de acciones que, desplegadas, generen resonancias en otros espacios de acción política.

En el caso de Rancière, este entiende el desacuerdo ya no como desconocimiento de lo que un interlocutor trata de decirle al otro, sino que este será el residuo existente entre el entendimiento de lo que señala un hablante. Por ejemplo, un interlocutor dice 'tierra', pero otro entenderá por 'tierra' algo diferente. Luego, la política se constituye en situación de desacuerdo, y es el desacuerdo lo que la hace existir. Con todo, Rancière va a decir que la política, más que ser un asunto de sujetos (ya constituidos), será problema de subjetivación, entendida como des-identificación; proceso en el que se desmarca del espacio de naturalización del sujeto (constituido). En este espacio, la diferencia será diferencia de una subjetivación a una identificación, diferente a cualquier parte identificable de una comunidad. Esto, a pesar de sí mismo, lleva a Rancière a decir que hay democracia en tanto haya 
interrupción singular del orden distributivo de los cuerpos en comunidades identitarias.

El desacuerdo es lo concerniente a la política, es el espacio constituyente de la política, lo cual implica que siempre hay diferencia en este espacio. El desacuerdo como condición para que exista el debate. Entonces, la condición de la política no será la de igualar las posiciones; no se trata de homogenizar sino de dar paso a un terreno de posibilidad. Por tal razón, Rancière dice que ahora se escucha como discurso lo que antes se escuchaba como ruido; el ruido es lo constitutivo de la diferencia.

De tal manera que la política como problema de modos de subjetivación se entiende como producción mediante una serie de actos, de una instancia o capacidad de enunciación que no eran identificables en un campo de experiencia dado. El problema no es buscar una identidad, una zona de comodidad desde la cual uno se ve identificado o representado. La subjetivación entendida como proceso permite habitar un espacio diferente donde dialogan formas-de-subjetivación en tanto que procesos no acabados. El sujeto de la política, podemos decir, son los modos de subjetivación (procesos) donde se es diferente de sí mismo como posibilidad del ser mismo. Dado que siempre se está en procesos de subjetivación, es decir, desidentificándose, entonces se habita el espacio de la diferencia donde los procesos son inacabados puesto que están siendo. Esto ayuda a Rancière para proponer la democracia como el espacio donde se dan los modos de subjetivación de la política.

En puente con lo anterior, la apuesta de Agamben está en señalar la forma-de-vida como vida política, es decir, posibilidad pensable que no se rige por prescripciones impuestas; conservando así el carácter de posibilidad, donde puede que algo pase o no, que una acción se despliegue o no. De este modo, la diferencia parece emerger aquí como potencia de vida del sujeto (constituyente) desde la cual se amplían los límites de lo establecido, de lo codificado, de lo habitual.

La diferencia en Agamben se puede leer en términos de forma-de-vida -la palabra forma es aquí la clave-. Podemos decir, vida no separable de su forma; nada se puede aislar y en su vivir se juega el vivir mismo. La potencia de vida, entonces, como forma-de-vida posible, terreno abierto de posibilidad donde se respeta el principio de diferencia en tanto que esta se habita. De esto resulta que este espacio se desmarca de cualquier igualación, no es homogeneizable. Es aquí donde podemos señalar la noción de diferencia, ya que siempre se es diferente en tanto posibilidad. La posibilidad de la política aparece como forma-de-vida, y la diferencia, como experiencia posible; espacio abierto a la posibilidad. 
Así las cosas, la política no se agota en el papel representativo, sino que debe llevar a crear otras cosas. Los contenidos y enunciados de la política no están dados por la política misma, están abiertos; situación constituyente de diferencia, de apertura. El ejercicio político consiste, pues, en profanar lo improfanable, en redefinir, en dessacralizar el campo político. Ahora bien, la acción profanadora ocupa un lugar sin lugar, un no-lugar, puesto que al profanar se está sacando lo sacralizado de un espacio y se está poniendo a circular en el espacio de la posibilidad.

\section{La Diferencia Como Puente Hacia Otros Modos-de-ser}

Digámoslo tan solo una vez más: el pensamiento político 'de la diferencia' no ocupa un lugar central en la discusión política contemporánea, pero esto no significa que no pueda hacerlo, al menos en un ejercicio como el que nos proponemos en un trabajo como este. Los pensadores que queremos presentar son susceptibles de agrupar no en términos de una relación de pensamiento y proyecto filosóficopolítico, sino más bien en términos del distanciamiento de cada uno de ellos frente a las propuestas identitarias que, al parecer, han constituido históricamente el eje central del pensamiento político -según nuestra hipótesis de lectura-. Para los autores, el problema ya no va a ser la construcción de significantes vacíos que deben ser llenados (pueblo, clase social, etc.), sino que será el de la creación de formas de vida otras, de nuevas subjetividades, de formas inéditas de asociación y acción política, etc. Su interés común es poder pensar formas otras de acción, que emerjan a partir de las resonancias entre acciones. Acciones entre acciones, entonces, como mónada conceptual del acontecimiento. Estas acciones, por lo mismo, están por realizarse constantemente -pues no están dadas de antemano-, y darían como resultado sustancias socio-filosóficas que ponen en su núcleo el devenir y la diferencia consigo mismas como estatuto principal, como condición de posibilidad.

De tal manera, lo que ahora hay son múltiples campos de posibilidad que pueden ser habitados; la diferencia se dibuja como aquello que se habita. Por lo tanto, habitando la posibilidad, el horizonte de lo posible se abre a la acción no-precodificable. Sin embargo, el hecho de que algo ocurra, de que emerja el acontecimiento, no cambia el hecho de que continúe abierto el campo de posibilidades: la posibilidad y la diferencia siempre son el escenario. En ese sentido, queda claro que el ejercicio político no puede quedarse en el papel de la representación y la constitución de identidad, ya que los contenidos de la política -pero, sobre todo, de lo político- no están dados, sino que son el espacio abierto constituyente que se habita con las acciones que devienen en todo caso procesos de subjetivación. 
Nociones del orden de 'clase', 'partido' o 'bloque histórico' ya no resultan del todo apropiadas en términos de acción política, puesto que obligan a pensar el sujeto como algo establecido y dado; además, con frecuencia son blancos fáciles de codificación, dificultando la acción política y los posibles cambios o transformaciones de los modos-de-vida. Por eso, frente a estas nociones clausurantes, sería necesario pensar en procesos de subjetiv-acción, donde no hay identificación social fija, sino cambio continuo de las condiciones mismas de producción de subjetividad. En la actualidad, se hace necesario tomar los campos económicos, tecnológicos, sociales, etc., como plataformas estratégicas de posibilidad a partir de las cuales re-inventar, crear nuevas cosas y posibilidades de acción que franqueen los límites que dichos campos presentan.

\section{REFERENCIAS}

Agamben, G. (2005). Profanaciones. Buenos Aires: Adriana Hidalgo Editora.

Agamben, G.. (2010). Medios sin fin. Notas sobre la política. Valencia: Pre-Textos.

Berardi, F. (2003). La fábrica de la infelicidad. Nuevas formas de trabajo y movimiento global. Madrid: Traficantes de Sueños.

Berardi, F. (2007). El sabio, el mercader y el guerrero. Del rechazo del trabajo al surgimiento del cognitariado. Madrid: Acuarela.

Berardi, F. (2010). Generación Post-Alfa: patologías e imaginarios en el semiocapitalismo. Buenos Aires: Tinta Limón.

Berardi, F., Jacquemet, M., y Vitali, G. (2003). Telestreet. Máquina imaginativa no homologada. España: El Viejo Topo.

Castro, E. (2008). Giorgio Agamben: una arqueología de la potencia. Buenos Aires: UNSAM.

Castro-Gómez, S. (2012). Zizek-Sloterdijk. [Curso magistral]. Pontificia Universidad Javeriana Bogotá.

Castro-Gómez, S. (2013). Michel Foucault y la estética de la existencia. [Archivo de video]: 26 de noviembre. Recuperado el 31 de marzo del 2014, de: http://www.youtube.com/watch?v=Q_RrI5mpLGw

Castro-Gómez, S (2014). Poder y Democracia Hoy. [Curso magistral]. Pontificia Universidad Javeriana. Bogotá.

Deleuze, G. (2007). “Deseo y placer”. En: Dos regímenes de locos. Textos y entrevistas (1975-1995). Valencia: Pre-textos.

Foucault, M. (2008). "Sobre la justicia popular. Debate con los maos". En: Un diálogo sobre el poder y otras conversaciones. Buenos Aires: Alianza.

Hardt, M., y Negri, A. (2006a). Imperio. Buenos Aires: Paidós.

Hardt, M., y Negri, A. (2006b). Multitud. Guerra y democracia en la era del imperio. Barcelona: Debolsillo. 
Lazzarato, M. (2006). Políticas del acontecimiento. Buenos Aires: Tinta Limón.

Lazzarato, M. (2007). La filosofía de la diferencia y el pensamiento menor. Bogotá: Universidad Central-Instituto de Estudios Sociales Contemporáneos, IESCO.

Negri,A. (2006). Movimientos en el imperio. Pasajes y paisajes. Barcelona: Paidós. Rancière, J. (1996). El desacuerdo: política y filosofia. Buenos Aires: Ediciones Nueva Visión.

Rancière, J. (s.f.) El odio a la democracia. Recuperado el 20 de febrero de 2014 de: https://anonfiles.com/file/1086c94b9623cc257614679ba10259f5

Virno, P. (2011). Ambivalencia de la multitud. Entre la innovación y la negatividad. Buenos Aires: Tinta Limón. 